\title{
Developing responsible owners in family business
}

\author{
Torsten Pieper (University of North Carolina at Charlotte) \\ Joseph Astrachan (Cornell Smith Family Business Fellow)
}

KEYWORDS: Management, Leadership, Family Business, Succession.

"When owners start talking about their rights rather than their responsibilities, a family business is in trouble“. (Smith Lanier)

\section{Introduction}

Management and organization research and education typically focus on strategies for increasing shareholder value and streamlining business operations. But they direct little to no attention on strategies for developing responsible business owners. This neglect is problematic, especially for family businesses. Responsible owners are crucial to the long-term survival of the family business (Pieper \& Astrachan, 2008). They provide not only financial capital to the business, but also human and social capital (Sirmon \& Hitt, 2003) including access to networks and other relationships that can foster entrepreneurial activities and benefit the business (Le Breton-Miller \& Miller, 2018). Responsible owners provide a support system to the business, and can see the business through times of economic hardship and recession.

Responsible owners have the ability to ask critical questions and hold the firm's management and leadership accountable for their decisions and actions. Entirely delegating this crucial task to a third party (e.g., the board of directors) or - in the worst case neglecting it entirely may create the danger of relinquishing control over the business and increasing the distance of the family owners to the business. A family business owner recently summarized the issue and related challenges rather succinctly, by stating "You can't outsource ownership. All other business functions, you can. But ownership, you simply cannot. So you either manage it, or you don't. And the latter is usually the beginning of the end for a family business."

Successors in a family business most often come from the ownership group and the more responsible and better trained the pool of potential successors, the better the selection will be. Responsible owners will value the family business and the family group over individual interests and support solutions and successor selections that are most conducive to the long-term survival of the family business.

Despite its importance, research has only recently started to explore how to cultivate responsible owners in family business (e.g., Binz Astrachan, Waldkirch, Michiels, Pieper, \& Bernhard, 2020). The purpose of this article is to contribute to this burgeoning stream of research. Toward this aim, we present strategies for developing responsible owners and, in particular, we address educational age-specific milestones, the role of self-esteem, shared values and family culture, and specific training methods. This advice can also be useful for any entrepreneur who is raising children and wants to instill good attitudes towards responsibility and money.

\section{Strategies for developing responsible owners in family business}

\section{Educational milestones}

Education is an important component in developing responsible owners.

The following table presents a list of age-specific tasks and the appropriate age ranges for these tasks. Each item is discussed in more detail in the following sections.

\section{Educational age-specific milestones}

Age-specific task Appropriate age (years)

Actions-consequences link 3-5
Copyright (C) 2020 The Authors. Entrepreneur \& Innovation Exchange is published at EIX.org. This is an open access article under the terms of the Creative Commons Attribution-NoDerivs License, which permits use and distribution in any medium, provided the original work is properly cited and no modifications or adaptations are made. View EIX.org Authorship Terms at https://eix.org/terms
FamilyBusiness 
Importance of future (no instant gratification)

\section{4-12}

Trade

\section{$5-8$}

Money

6-10

Investing

8-12

Separation of ownership10-15 and management

Emotional differentiation

Statements of financial18-30 condition: Balance sheet, P\&L, Cash flows

Financial analysis (Ratios,24-35

CAPM, DuPont, EVA, Managerial finance framework)

Developing self-esteem Life-long task

Learning from failure Life-long task

\section{Actions-consequences link}

Actions-consequences link refers to the fact that actions have consequences and that individuals should be knowledgeable about this link. A crucial role of owners is to hold the management and employees of the company accountable for their actions. In order to do so, owners must have a sense of responsibility themselves. Otherwise, they risk holding managers and employees accountable to standards different from their own, which leaves room for ambiguity and creates uncertainty. Ages 3-5 represent the appropriate age range for instilling the actions-consequences link because this is the developmental stage where children start recognizing their own limits and are able to make choices between opposing goals.

The crucial component in developing this link is that parents should establish clear, consistent criteria through words and action. So when a child engages in a certain behavior, both parents will respond in the same manner - independent of what the child does. This has also been shown to be a key to developing self-esteem (Seligman, 1974). Self-esteem allows for more accurate communication, both in forming messages and in receiving them. People with self-esteem are better at understanding subtleties in communication and are far less likely to misinterpret others due to insecurities (they do not take things personally). Consistency in the actions-consequences link builds self-esteem ${ }^{1}$ because the child's "world" is experienced as predictable which allows them to make choices with predictable outcomes. Indeed, children learn that, within the boundaries of what they have experienced, they can exert some control over their environment (e.g., if I want to be scolded, I act one way and if I want to be praised, I act another).

\section{Importance of future (no instant gratification)}

As the actions-consequences link becomes clear, the timing is appropriate for teaching delayed gratification. We move our focus from helping the child learn that certain behaviors can lead to predictable outcomes in the short run to certain behaviors lead to a predictable outcome after some delay. There has been a great deal of research (e.g., Mischel, 2014) that convincingly concludes the ability to delay gratification in childhood is a superior predictor of success as an adult (e.g., happier, less likely to have committed a crime, educational achievement, more and more satisfactory relationships, vocational achievement).

Delaying gratification with its many positive outcomes is a desirable trait in business life later on when reward is often a function of endurance, perseverance and patience. Parents can develop the acceptance of delayed gratification in their children by making them wait to get what they want and developing an expectation that getting what you want is the result of something that you do. Obviously, the amount of delay or the activity engaged is contingent upon the type of desire, children's age and other factors. Generally, parents can start with short delays and gradually extend them to teach, at the unconscious and conscious levels, the importance of delayed gratification.

We understand well that it is often difficult for parents with wealth to have the discipline to allow their child to experience delayed gratification since they have at their disposal the ability to please their children without delay and from what appears to be a natural desire to provide one's children a happier and better life than we had 
ourselves. Nonetheless, this attitude can rob the child of the ability to have a happy and fulfilling life as an adult. There is a direct analogue in the business; people who can delay gratification generally have a baseline discount rate that is lower than those who need to consume things immediately. In business, for example, during the capital allocation process, lower discount rates lead to more benefit from investing.

\section{Trade}

Trade overlaps with teaching the value and use of money and should be taught between the ages of 5-8. Children who develop a good understanding of the motivations and underlying procedures of trade can bank on this understanding later in life. Trade also emphasizes reciprocity, which is crucial for being a good owner and a reliable family member. Reciprocity means, when you make a trade, it should be a fair trade; otherwise, one party gets disadvantaged to the benefit of the other which most often will have negative consequences for the partnership in the long run. As part of understanding trade, children should understand that some things are taken away from them in exchange for receiving other things. Moreover, receiving those things may occur at a later time; hence, being able to delay gratification represents another benefit in the context of trade).

\section{Money}

Learning of the meaning and use of money is another important milestone. Teaching children the value and use of money at a young age, around the ages of 6-10 is advisable. It is crucial that children learn that money is not just coin and paper but represents the value of things and is a promise to pay in goods or services (this is the concept of money as a tradable IOU). Understanding the need to give up some things in order to acquire others will allow them to appreciate their value. Their understanding of money's role and the spending and saving habits they develop early in life will shape their attitudes toward a wide array of financial matters in adulthood.

\section{Investing}

In learning about money and trade, it is important to stress the value of the future, as in the process and consequences of investing, around the ages of 8-12. A crucial component is the maxim, learned around the age of 4 and continuing through this phase, that there is no instant gratification.
Knowing the importance of the future is a crucial condition for understanding and making investment decisions. This is especially true for family businesses, where creating long-term wealth is typically more important than maximizing short-term profit. Investing involves learning about risk and reward (i.e., the need to delay gratification to have higher rewards in the long run), and understanding types of investments (e.g., direct investments, stocks, bonds, securities). Having children select a stock to invest in, visiting that company and using its products helps them understand elements of ownership. This understanding helps them place others before themselves, which is a true hallmark of mature responsibility.

Perhaps the last things to learn in understanding investing are the notions of the Time Value of Money and the cost of debt and equity. The former refers to the fact that money very often loses value over time and the latter concerns the idea that money is like any other thing one might rent and therefore has a cost (interest for a loan and desired Return on Equity for ownership). It is often difficult to understand the differences between loans and equity and here is where we advise introducing more forcefully the concept of risk and why equity generally has a higher cost. Legally, loans have very limited risk for they are the first people to get paid back in the case of a bankruptcy and have no risk if the company gets sued whereas owners are repaid last in a bankruptcy and their personal wealth independent from the business can be at risk, albeit quite small, when the company is sued.

\section{Separation of ownership and management}

Separation of ownership and management should be taught during ages 10-15. Key to this milestone is the understanding and acceptance that ownership does not automatically make one a manager or future leader. The different roles need to be defined clearly and the requirements for each function (owner and manager/ leader) need to be explained and commonly accepted. This will prevent feelings of entitlement and wrong and unmet expectations ${ }^{2}$ from causing conflict in both the family and the business. Understanding boundaries in general helps children develop the ability to delegate and cede control without giving-up oversight and accountability; qualities needed when owning or leading any large organization. For further guidance and practical tools for ownership roles and competence assessments, please see Binz Astrachan et al. (2020). 


\section{Emotional differentiation}

Emotional differentiation is a critical developmental challenge during ages 18-25. Put simply, emotional differentiation is when the emotions of others do not cause an inappropriate emotional reaction in oneself (Bowen, 1976). A apt example is when a mother suddenly comes crying into a room where a family is having a serious discussion about the business and without a word having been said, everyone falls apart without knowing or asking why or what she is upset about. The mother's emotions have caused an emotional cascade in the other family members. Achieving emotional differentiation is a difficult task and requires hard, consistent work. In addition, since no two individuals are the same, each requires a different path.

The benefits of differentiation are many and include accurate communication and the interpretation of others, reacting appropriately to the situation (not too overreacting or appearing inappropriately apathetic), and generally taking one's emotional needs out of the equation when making decisions that affect the lives of others. In a family context, differentiation is needed to achieve adult relationships as siblings that never risk regressing into childhood behaviour patterns.

\section{Statements of financial condition}

Learning and understanding how to read balance sheets, profit \& loss (P\&L) statements, and statements of cash flows (and understanding how they connect) are important milestones at ages 18-30. This is akin to learning the basic words in the language of the suppliers of capital. Future leaders who have this ability can interpret financial and business information provided them and gain a better understanding of the situation at hand from a high level. This is especially important for future owners who do not have a business education and are less familiar with these matters. Understanding relevant business information allows future owners to ask the right questions and hold management and employees accountable for their decisions and actions.

\section{Financial analysis capabilities}

Finally, financial analyses - such as the Capital Asset Pricing Model (CAPM), Net Present Value (NPV), DuPont Model, Economic Value Added (EVA) and managerial accounting - are important developmental milestones to be taught during ages 24-35. The capability to assess the viability, stability and profitability of a business, business unit or project is critical in deciding whether or not to make or maintain an investment. Specifically, it provides information about whether to continue or discontinue an operation or business unit, whether to make or buy materials necessary for the production process, or whether to use debt or equity to invest, to mention but a few critical business decisions. Knowing about and being able to process these decisions themselves allows future owners and leaders to think more critically and to make better-informed decisions for their businesses, and for their personal wealth and that of current and future generations.

While the above educational milestones focus on the individual, another crucial element, especially among siblings, but also other family members, is to force them to make decisions together. Making decisions together not only helps build a routine for working together, but paired with self-esteem - it also establishes trust. This should be done at all ages.

\section{Developing self-esteem}

As mentioned in the action-consequences link section, developing self-esteem in individuals is essential to developing sustainable leadership abilities. Self-esteem, an individual's evaluation of his or her own worth, is important because individuals with a healthy level of selfesteem trust their own judgment and feel secure enough to express their thoughts, and are sensitive to the needs and feelings of others.

Self-esteem can be developed in the following ways:

- Consistency in childhood: This is the most important of all the tactics described here. Parents should not respond differently to the same behavior. Coherence among words and actions is important in raising children. It allows children to anticipate the consequences of their behavior and thereby helps enforce guidelines for behavior.

- Actions and consequences are connected: As indicated earlier, realizing that actions and consequences are connected to one another allows children to trust their judgment and develop their sense of self-esteem.

- Sense of control over self: Having a sense of control over oneself gives individuals confidence to act independently and also to support others in need.

- Mastery of tasks: Mastering tasks is important because it gives a sense of accomplishment and 
pride. It is important that children master their assigned tasks by themselves and make mistakes in order to learn and improve for the future. Recovering from mistakes is essential to self-esteem (more on this below).

- Accurate feedback: Parents should not overpraise their children when they perform below what was expected. But at the same time, they should also not spare their praise when their children perform above expectations.

Furthermore, in addition to being appropriately critical, with regard to praise, rather than giving general praise, it is important that parents are specific about what particular actions or behavior of the child they are praising. Specific praise will give the child a sense of control over his or her actions and allow the child to adjust his or her behavior accordingly. Accurate and specific feedback instils confidence and reflects consistency. And perhaps most importantly of all, it communicates that parents trust their children by telling them and trusting them with the truth.

- Familial support: Familial support is important because it shows the individual that he or she is not alone but has a support system on which to rely. The presence of such a safety net gives confidence to encounter and deal with failures and difficulties.

- Being listened to: Knowing one is heard shows that others care and are there to listen to concerns and eventual problems. Ultimately, it shows individuals that they are valued. Knowing that others are there to listen provides a sense of security that individuals with self-esteem can then render to others.

\section{Learning from failure}

Another crucial lifelong task is resilience and the ability to learn from failure. Failure can be the most impactful teacher. We all tend to remember our failures more than our successes. Knowing what not to do can reduce risk often more than know what to do. On the other hand, failure can be a crutch and tactic in a manipulative family dynamic where victims are coddled and given more attention. Demonizing failure can be used to stifle initiative and action and maintain dysfunctional control.

To teach our children to learn from failure, and the power of resilience and persistence, requires some constant attention. One simple tactic is to decide at every age how long you would allow a child to suffer from a mistake they might make, before interceding to prevent a mistake. For example, when your child is 4, you might allow them to make a mistake in which the child would suffer for no more than 20 minutes, and at age 8 that might be extended to 3 hours and so on. In this way of thinking, your child is not considered an adult until you would allow them to make a mistake that would cause life-long suffering. One benefit of this approach is that it reduces the likelihood that your children will assert their independence in self-destructive ways, as it has encouraged independence (albeit within guiderails) from a young age. Another benefit is that your children learn they have to ask for opinions and advice in order to not suffer and become used to asking for help and relying on others in ways that do not diminish their selfesteem. An extra special outcome of this process is that it generally results in you being one of the lucky few parents who do not have to nag your children, as they will very likely come to you rather frequently for your insights and opinions.

So far, we have talked about educational milestones and self-esteem as important building blocks for developing future family business owners. These measures should be tightly integrated into a set of shared values and the specific family culture. We look at these aspects in some more detail in the following section.

\section{Shared values and family culture}

Shared values represent the fundamental beliefs and principles that constitute the culture of groups or organizations and guide the decisions and behavior of their members (Schein, 1985). A set of shared values is in many ways a set of guidelines or intents, commonly accepted and internalized by the members of the group or organization. For example, if one of the family values is "we do not lie," family members and, by extension, employees in the business know that lying is unacceptable.

Families are "primary groups" that socialize their members from an early age and form the basis for an individual's ideals. Early socialization provides families unlike other groups - with the advantage to instill shared norms, beliefs and values in their members over an extended period of time. Therefore, it is important for a family to determine what its values are and to reiterate these values, through words and actions, consistently and on many occasions. 
Values determining what goals the family wants to achieve and how it wants to achieve these goals help regulate individual behavior. Values also help individuals understand the boundaries of appropriate behavior: strong, agreed-upon values help family members and employees alike know which behaviors are acceptable or unacceptable. In this respect, shared values help coordinate and synchronize the actions of family business owners, their leaders and employees, and help build cohesion in the family and the business.

A set of shared values and the early internalization of such values may also help to harmonize the preferences and choices of family members, thereby reducing potential ambiguity and conflict. This is especially important when the ownership group has grown large and preferences can no longer be assumed to be similar. Shared values also communicate to in-laws who marry into the family what is important to the group, and this further helps reduce potential ambiguity and conflict.

Given their crucial role in guiding behavior and coordinating actions, shared values of the ownership group should be integrated into the organization via its culture. A culture based on stewardship seems conducive to developing shared values and therefore appears particularly suitable to family businesses (see also Le Breton-Miller \& Miller, 2015). Stewardship stems from medieval times when a "steward" was assigned to prepare a young prince for his future reign and, ultimately, make him a successful king. The meaning has not changed much nowadays. Individuals with a stewardship mentality are good team players who do what is in the best long-term interest of the group or organization to which they belong. A stewardship culture is one that nurtures and facilitates responsible, proorganizational and trustworthy behavior among individuals. While a stewardship culture should ultimately permeate the entire organization, family business owners should lead by example. Through that example, the value of stewardship will likely diffuse throughout the enterprise.

Stewardship works best where individuals are intrinsically motivated and identify with the group or organization to which they belong. These conditions are commonly found in business families with high levels of cohesion (i.e., where the members are close to one another) and capable of transferring this closeness and trust to their managers, employees and other stakeholders. Stewardship is commonly associated with long-term wealth creation rather than short-term profit maximization. Strong indicators of a stewardship culture among family businesses are statements like "We want to build a business that will last for generations and contribute to the greater benefit of society," or "Our goal is to pass this business along to the next generation in a better condition than it was given to us."

As discussed earlier, developing future owners in a family business should begin in early childhood. Educational milestones, development of self-esteem, internalization of family values and developing a stewardship mentality are attitudes that should form part of early upbringing. It includes educating family members to build a consciousness of self and others, and to understand money and other tangible assets, thus preparing them for becoming responsible owners. Following childhood, further specific training measures can be taken to prepare the next generation for their leadership role. We will turn to these measures in the following section.

\section{Specific training}

Before we discuss the various specific training measures to develop future leaders, it is important to reiterate that whatever programs a family business puts in place to develop future owners must fit that specific family business' culture and aim to reinforce cohesion in the ownership and family group (Binz Astrachan, Astrachan, Kotlar, \& Michiels, in press); our research shows that cohesion is a crucial element for securing the long-term survival of the family business (Pieper \& Astrachan, 2008).

When ready, next-generation members should attend family meetings and shareholder assemblies and become familiar with extended family, helping them identify with the larger family group and feel like they belong. As adolescents, next-generation members are further sensitized to the fact that the business represents an important emotional asset, which increases their attachment to the family business. Professional training - such as seminars on financial management - and regular meetings around the business allow next-generation members to apply their emergent financial skills in a business realm and help strengthen their identification with the family business and the ties among next-generation members. These activities also help reiterate and internalize core values of the extended family, and thus increase bonding to the 
family and business. Regular meetings also help nextgeneration members to identify potential candidates for future leadership positions early on so that a widely shared and well-informed decision can be reached later on about who is most capable of leading the family business.

Plant tours and internships provide additional opportunities for developing responsible owners in that these actions help build a deeper knowledge about the business and allow individuals to identify with the business, its employees and products. Getting to know first-hand what the business does and meet employees instils a sense of responsibility for the family business legacy.

Apart from formalized training opportunities, learning from good role models is another opportunity for developing future owners in family business. Good role models can be not only family members, but also nonfamily members, individuals who live the values and display the kind of responsibility for which the family strives. Families should consider visiting other business families whom they respect and consider to do a firstrate job in managing both the family and the business. Such visits provide opportunities to exchange and learn from others to improve one's own skills.

\section{Conclusion}

Our key suggestions for developing responsible owners in family business can be summarized as follows.

- Develop a business sense in childhood: The earlier business sense is developed, the sooner children adapt a mindset that is conducive for family business. The various educational milestones discussed earlier are all geared toward building this foundation. They should be supplemented with developing self-esteem in individuals.

- Learn to work together and make joint decisions: A crucial element - especially among siblings, but also other family members - is to force them to make decisions together. Making decisions together not only helps build a routine for working together, but - paired with selfesteem - also establishes trust.

- Accept delayed gratification: As mentioned earlier, the ability to delay gratification in early childhood comes with many benefits in later life. This trait will be of special importance when making financial, investment and business decisions for the family business, since sacrificing short-term gains for long-term value creation typically facilitates survival in the long run.

- Integrate good values, morals and ethics: Good values, morals and ethics are the glue that cements everything the family does to develop responsible owners and future leaders. It does not really matter what these values are, as long as most (ideally all) members of the family and the business agree to and share them. When values are shared by everyone, they provide guidelines for behavior, they communicate expectations, and they harmonize preferences, which together ultimately increase the cohesion of the owning family and the business overall.

- Understand stewardship: A stewardship attitude and culture seems most appropriate for longterm family business survival. Stewardship instils a sense that serving the business is a more important responsibility than serving particular individual interests.

- Attend family meetings: Attending family meetings allows for good communication and development of strong relationships. When the family has grown large, regular meetings encourage relationships and bonding with the extended family.

Finally, we encourage parents not to shield their children from knowledge, good or bad. Children should be given exposure to a broad array of knowledge to make them well-versed and responsible future owners and leaders of the family business.

\section{References}

Binz Astrachan, C., Astrachan, J. H., Kotlar, J., \& Michiels, A. (in press). Addressing the theory-practice divide in family business research: The case of shareholder agreements. Journal of Family Business Strategy.

Binz Astrachan, C., Waldkirch, M., Michiels, A., Pieper, T. M., \& Bernhard, F. (2020). Professionalizing the business family: The five pillars of competent, committed and sustainable ownership. A research report sponsored by the FFI 2086 Society. Available at https://digital.ffi.org/pdf/wednesday-edition/2020/januar y-08/ffi_professionalizing_the_business_family_v2.pdf 
Bowen, M. (1976). Theory in the practice of psychotherapy. Family therapy: Theory and practice, 4(1), 2-90.

Le Breton-Miller, I., \& Miller, D. (2015). Learning stewardship in family firms: For family, by family, across the life cycle. Academy of Management Learning \& Education, 14(3), 386-399.

Le Breton-Miller, I., \& Miller, D. (2018). Beyond the firm: Business families as entrepreneurs. Entrepreneurship Theory and Practice, 42(4), 527-536.

Mischel, W. (2014). The marshmallow test: Understanding self-control and how to master it. Random House.

Pieper, T. M., \& Astrachan, J. H. (2008). Mechanisms to assure family business cohesion: Guidelines for family business leaders and their families. Cox Family Enterprise Center.

Schein E., H. (1985). Organizational culture and leadership. Jossey-Bass.

Seligman, M. E. (1974). Depression and learned helplessness. John Wiley \& Sons.

Sirmon, D. G., \& Hitt, M. A. (2003). Managing resources: Linking unique resources, management, and wealth creation in family firms. Entrepreneurship Theory and Practice, 27(4), 339-358.

[1] (denied:applewebdata://1A185882-D1C8-4135-8697-0 DDAEFDA48F6\#_ftnref1) There is more information on self-esteem toward the end of this article.

[2] (denied:applewebdata://1A185882-D1C8-4135-8697-0 DDAEFDA48F6\#_ftnref2) Unmet expectations are dangerous as they can be experienced as betrayal by family members. This adds greater importance to the need to have expectations clearly defined and frequently reviewed in business families. 